\title{
Friction in Forming of UD Composites
}

\author{
U. Sachs, R. Akkerman, R. ten Thije, M. de Rooij \\ University of Twente, Production Technology Group, P.O. 217, 7500 AE \\ Enschede, The Netherlands \\ u.sachs@utwente.nl
}

The aerospace and automotive industry show an increasing interest in thermoforming processes of unidirectionally (UD) reinforced thermoplastic laminates. Especially, hot stamp forming provides a fast automated process, which allows tailored and complex products. In order to develop a simulation tool for predicting failure like wrinkling or tearing of the product, a thorough understanding of the underlying deformation mechanisms is required.

One of these deformation mechanisms is inter-ply or tool/ply friction. A constitutive model that assumes hydrodynamic lubrication (HL) for fabric reinforced thermoplastics was introduced by Akkerman et al [1]. This model is essentially based on the fabric weave geometry and assumes HL on a meso-mechanical level. However, this model is not easily applicable to UD geometries. Despite the lack of a physical model for UD laminate friction, the frictional behaviour is assumed to be HL. This is indicated by own experimental data and is also assumed by Murtagh [2]. The actual film thickness is unknown, however.

An HL model can also be derived on a macro-mechanical level by assuming not perfectly parallel surfaces that can tilt with respect to each other. This is commonly known from the Michael/Kingsbury tilting pad [3]. This model shows that very small misalignments which are difficult to control will influence the friction significantly.

A friction test set-up was developed at the University of Twente [4], in which a laminate is pulled at constant velocity, while clamped by two blocks at processing temperature. The set-up operates in a standard mechanical testsystem. The blocks are self-aligning and the spacing between the blocks is measured at four corners with micrometer accuracy. During the experiments we observed a tilt angle that changes significantly during the friction test. On the basis of a parameter study we will present the significance of these variations on the friction. We will compare the influence of the misalignment for UD and fabric weave geometries. A new constitutive model will be derived that is based on a macro- and meso-mechanical level.

\section{References}

1 R. Akkerman, M.P. Ubbink, M.B. de Rooij and R.H.W. ten Thije. Tool-ply friction in composite forming, 10th Int ESAFORM Conf, 2007

2 A.M. Murtagh, J.J. Lennon and P.J. Mallon, Surface Friction Effects related to Pressforming of Continuous Fibre Thermoplastic Composites, Composites Manufacturing 6:169-175, 1995

3 A. van Beek, Tribologie-Levensduur en prestatie (in Dutch) Delft University of Technology - Tribology Department, 2001

4 R. H. W. ten Thije and R. Akkerman, Design of an experimental setup to measure tool-ply and ply-ply friction in thermoplastic laminates, International Journal of Material Forming, 2:197-200, 2009 